\title{
THE EFFECT OF LARGE DOSES OF VITAMINS A, B, C AND D ON THE INCIDENCE OF UPPER RESPIRATORY INFECTIONS IN A GROUP OF RHEUMATIC CHILDREN ${ }^{1}$
}

\author{
BY ANN G. KUTTNER \\ (From Irvington House, Irvington-on-Hudson, N. Y.)
}

(Received for publication July 10, 1940)

Most students of rheumatic fever agree that upper respiratory infections, especially those associated with Group A beta hemolytic streptococci, are often followed by a recurrence of rheumatic symptoms. Any measures which might tend to lessen the incidence of upper respiratory infections among rheumatic subjects are therefore worthy of study.

The occurrence of severe spontaneous infections in animals on vitamin A deficient diets suggested that this vitamin might play an important rôle in the resistance of individuals to upper respiratory infections (1). Since the characteristic lesion of vitamin A deficiency is the degeneration of specialized epithelium, it was thought that the mucous membranes might be peculiarly susceptible in individuals whose diet was low in vitamin A. In spite of numerous studies (2), however, the value of an excess of vitamin $A$ as a means of increasing resistance to upper respiratory infections has not been established, and several observers conclude that there is no justification for calling vitamin A the "anti-infective" vitamin (3).

It seemed possible that the addition of several vitamins might be more effective in increasing the general resistance to infection than the addition of vitamin $\mathrm{A}$ alone. As far as we have been able to determine from a review of the literature, Stone (4) and her co-authors are the only workers who have tried the addition of several vitamins. They studied the effect of adding concentrates of vitamins $A, B_{1}, B_{2}$ and $D$ to the diet of 11 college students for $3 \frac{1}{2}$ months, from November 15 th until March 1st. The exact dosage of each vitamin was not stated. The students were selected because their general physical condition was poor and they were known to be very susceptible to colds. These authors were of the opinion that

1 This work was aided by a grant from The Commonwealth Fund. incidence of upper respiratory infections was reduced during the period that the vitamins were given. It is obvious, however, that the number of individuals studied was too small to warrant drawing definite conclusions.

\section{Plan of study}

It was thought that the effect of the addition of an excess of vitamins to an average diet could be more accurately determined in an institution where the children were under constant medical supervision and where the incidence and types of upper respiratory infections were carefully studied.

\section{PROCEDURE}

One hundred and eight rheumatic children, 66 girls and 42 boys, ranging in age from 7 to 14 years, were admitted during the summer and fall months and remained in the institution from December 1st until the end of May. Children with definite histories of one or two attacks of polyarthritis or carditis without severe cardiac damage were selected. Temperatures and pulse rates were taken three times daily. Leukocyte counts, hemoglobin determinations and sedimentation rates were done routinely every 3 to 4 weeks and more often when necessary. Throat cultures to determine the presence of Group A beta hemolytic streptococci were taken every week. Additional cultures were taken on two successive days if a child developed symptoms of any kind. Antistreptolysin titers were also determined at frequent intervals.

The effect of the addition of vitamins A, B complex, $C$ and $D$ was studied during two successive winters.

The 108 children were divided into two groups, one group receiving the regular diet with the addition of vitamins and the other group receiving the regular diet without additional vitamins. The children in the two groups were matched as nearly as possible in regard to rheumatic history, age, and general condition.

During 1939, vitamins A, B complex, C and D 2 were

2 During 1939, vitamins A, D and B complex were donated by Lederle Laboratories, Inc. One-half of the vitamin $C$ was given by Chas. Pfizer \& Sons (tableted by Lederle Laboratories, Inc.) and remainder by Merck \& Co., Inc. During 1940, the vitamins were obtained at cost through the courtesy of Lederle Laboratories, Inc. 
given daily for 5 months from January 1st until June 1st. During the winter of 1939 to 1940 , the same vitamins were given daily from December 1st, 1939 until May 1st, 1940. The following dosage was used:

Vitamin A 15,000 U.S.P. units 1 capsule daily, equiv-

Vitamin D 1,870 U.S.P. units $\int_{\text {oil }}$

Vitamin $C \quad 2,000$ International units

Vitamin $B_{1} \quad 1,000$ International units

$B_{2} \quad 480$ Bourquin-Sherman units

B. 40 "Rat Day" units

Filtrate (Factor (s))-approximately $408 \mathrm{cc}$. Growth units (Rat or Chick)

Nicotinic Acid or derivatives (pellagra curative) equivalent to 50 grams of whole liver

RESULTS

Winter of 1938 to 1939

Beginning in February 1939 and continuing through May, 32 children developed upper respiratory infections associated with the presence of Group A beta hemolytic streptococcus of a single type, Type 4. Most of the children complained of sore throat and had temperatures of $101^{\circ}$ to $103^{\circ} \mathrm{F}$. for 2 or 3 days accompanied by elevated leukocyte counts. Type 4 streptococci were isolated from throat cultures and were usually present in large numbers. The monthly incidence of these infections and their distribution among children on vitamins and among those serving as controls is presented in Table I.

TABLE I

Streptococcus pharyngitis

\begin{tabular}{|c|c|c|c|}
\hline Months & $\begin{array}{c}\text { Total } \\
\text { number } \\
\text { of cases }\end{array}$ & $\begin{array}{l}\text { Number of children } \\
\text { on vitamins gince } \\
\text { January } 1,1939\end{array}$ & Controls \\
\hline \multirow[t]{2}{*}{ 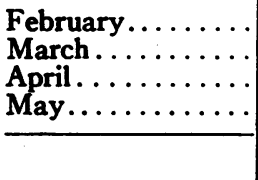 } & $\begin{array}{r}4 \\
17 \\
6 \\
5\end{array}$ & $\begin{array}{l}3 \\
9 \\
5 \\
0\end{array}$ & $\begin{array}{l}1 \\
8 \\
1 \\
5\end{array}$ \\
\hline & 32 & 17 & 15 \\
\hline
\end{tabular}

None of the 32 children developed rheumatic manifestations following these upper respiratory infections.

Weight. The average gain in weight during the 5-month period for the boys on vitamins and the boys serving as controls was the same. The average gain in weight among the girls receiving vitamins was 1.5 pounds more than among the girls serving as controls.

\section{Winter of 1939 to 1940}

During this year two types of upper respiratory infections were prevalent among the children: an outbreak of influenza ${ }^{3}$ characterized by fever, malaise and a low leukocyte count; and a series of sore throats accompanied by fever and elevated leukocyte counts. Throat cultures from the influenza cases were uniformly negative for beta hemolytic streptococci. Throat cultures from the cases of pharyngitis in every instance showed Group A beta hemolytic streptococci of a single type, Type 27.

The monthly incidence of influenza and its distribution among children receiving vitamins and those serving as controls is presented in Table II.

TABLE II

Influensa

\begin{tabular}{c|c|c|c}
\hline \hline Months & $\begin{array}{c}\text { Total } \\
\text { number } \\
\text { of cases }\end{array}$ & $\begin{array}{c}\text { Number of children } \\
\text { on vitamins since } \\
\text { December 1, 1939 }\end{array}$ & Controls \\
\hline February........ & 26 & 15 & 11 \\
March......... & 25 & 11 & 14 \\
\hline & 51 & 26 & 25 \\
\hline
\end{tabular}

The monthly incidence from January to May of the cases of streptococcus Type 27 pharyngitis and their distribution among children on vitamins and those serving as controls is presented in Table III.

TABLE III

Streptococcus pharyngitis

\begin{tabular}{|c|c|c|c|}
\hline Months & $\begin{array}{c}\text { Total } \\
\text { number } \\
\text { of cases }\end{array}$ & $\begin{array}{c}\text { Number of children } \\
\text { on vitamins since } \\
\text { December 1, } 1939\end{array}$ & Controls \\
\hline \multirow[t]{2}{*}{ 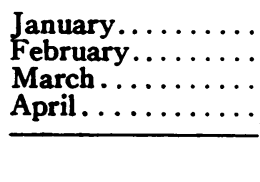 } & $\begin{array}{r}15 \\
2 \\
6 \\
1\end{array}$ & $\begin{array}{l}6 \\
1 \\
4 \\
0\end{array}$ & $\begin{array}{l}9 \\
1 \\
2 \\
1\end{array}$ \\
\hline & 24 & 11 & 13 \\
\hline
\end{tabular}

3 Dr. Thomas Francis of New York University College of Medicine was kind enough to examine material from several of these cases for the presence of influenza virus. A strain of epidemic influenza virus was isolated. Neutralization tests with acute and convalescent sera from 3 patients showed a rise in antibody titer during convalescence. 
Comparison of rheumatic activity in children receiving vitamins and those serving as controls

Of the 13 children (Table III) who were not receiving vitamins and who contracted Type 27 infections, only one developed a rheumatic recurrence following a latent period.

Of the 11 children who were receiving vitamins and who contracted Type 27 infections, 3 developed rheumatic recurrences following a latent period. One of these 3 children had the Type 27 pharyngitis on January 17, 1940 when he had been receiving vitamins for 53 days. He developed rheumatic symptoms on February 9, 1940 after a latent period of 18 days. The other 2 children developed pharyngitis associated with streptococcus Type 27 on March 25 and March 26, 1940, respectively, when they had been receiving vitamins for nearly 4 months. The pharyngitis in these 2 girls was followed by rheumatic manifestations; in 1 the latent period was 22 days, and in the other 20 days. The administration of vitamins in these 3 children was not interrupted at any time.

In view of the work of Rinehart and his coworkers and of others (5), it is of interest that these 3 children developed rheumatic recurrences in spite of the administration of large amounts of vitamin $\mathrm{C}$ for a considerable period of time before the rheumatic manifestations. All 3 of these children had been here during two successive winters (1938 to 1939 and 1939 to 1940) and had received vitamins for a 5-month period during both years. Since the number of children who were on vitamins and who developed rheumatic symptoms was so small and since no chemical studies were made to determine how well the cevitamic acid was retained by these children, no conclusions in regard to the value of vitamin $C$ in preventing the development of rheumatic fever can be drawn. However, our findings, limited as they are, are in accord with those of other workers (6).

Weight. In contrast to the previous year, the average gain in weight of the boys receiving vitamins was slightly greater than of the boys serving as controls. On the other hand, the gain in weight among the two groups of girls was the same. Children receiving institutional care usually tend to gain and no definite improvement attributable to the additional vitamins was apparent.

\section{DISCUSSION}

In previous studies to determine the value of one or more vitamins in reducing the incidence of upper respiratory infections, the subjects in most instances have been ambulatory, and it was, therefore, difficult to be certain that the vitamins had actually been taken. In some of the reports, the individuals who received the vitamins were selected because they were thought to be unusually susceptible to colds. In cases where a reduction in the incidence of upper respiratory infections seemed related to the intake of increased amounts of vitamins, it was usually based on the history given by the individual as to the number of colds he had had during the previous winter. In some of the reports no studies of control groups were included.

In this study a group of 108 rheumatic children ranging in age from 7 to 14 years was studied under constant conditions from December 1st until the end of May. The children lived and went to school in the same building. They had no contact with other children, and each child was only permitted two adult visitors every 6 weeks.

The administration of the vitamins was carefully supervised by the nursing staff. The children in the control group and in the group receiving vitamins were matched as closely as possible in regard to age, rheumatic history and general condition, so as to be comparable. Twentyone children, 9 boys and 12 girls, who had received vitamins during 1939 and who remained here during 1940, were given vitamins two years in succession.

During each of the two winters of the study, cases of pharyngitis associated with a single type of streptococcus (Type 4 in 1939 and Type 27 in 1940) were prevalent. The incidence of these infections in each of the years among the children receiving vitamins and those in the control group was essentially the same.

During February and March 1940, 51 children had influenza; 26 of these children were receiving vitamins and 25 were in the control group.

There was no significant difference in weight gain between the two groups. 


\section{CONCLUSIONS}

1. No evidence was obtained to suggest that the addition of large doses of vitamins A, B complex, $\mathrm{C}$ and $\mathrm{D}$ to an ordinary well-balanced diet reduces the incidence of upper respiratory infections.

2. Three children who had received the additional vitamins for a considerable period of time developed rheumatic symptoms following an attack of streptococcus pharyngitis.

3. Children on the regular diet without additional vitamins and those on the regular diet with additional vitamins gained weight at approximately the same rate during the 5-month period.

\section{- BIBLIOGRAPHY}

1. McCollum, E. V., The supplementary dietary relationships among our material foodstuffs. J. A. M. A., 1917, 68, 1379.

2a. Cameron, H. C., Effect of vitamin A upon incidence and severity of colds among students. J. Am. Dietet. A., 1935, 11, 189.

b. Tress, E. M., Vitamin " $A$ " as prophylactic against common "cold" in groups of school children. Am. J. Digest. Dis. and Nutrition, 1935, 1, 795.

c. Gardner, E. L., and Gardner, F.' W., Vitamin A and colds. Am. J. Dis. of Child., 1934, 47, 1261.

d. Holmes, A. D., et al., Cod liver oil : 5-year study of its value for reducing industrial absenteeism caused by colds and respiratory diseases. Industrial Med., 1936, 5, 359.

e. Robertson, E. C., The vitamins and resistance to infection. Medicine, 1934, 13, 123. 3a. Wright, H. P., Frosst, J. B., Puchel, F., and Lawrence, $M$. R., Vitamin " $A$ " and the common cold. Canadian M. A. J., 1931, 25, 412.

b. Barenberg, L. H., and Lewis, J. M., Relationship of vitamin $A$ to respiratory infections in infants. $J$. A. M. A., 1932, 98, 199.

c. Clausen, S. W., Limits of anti-infective value of provitamin A (carotene). J. A. M. A., 1933, 101, 1384.

d. Hess, A. F., Lewis, J. M., and Barenberg, L. H., Does our dietary require vitamin $A$ supplement? J. A. M. A., 1933, 101, 657.

e. Shibley, G. S., and Spies, T. D., Effect of vitamin A on common cold. J. A. M. A., 1934, 103, 2021.

4. Stone, F. G., Bird, M. S., and Field, H. E., Vitamins $A, B_{1}, B_{2}$, and $D$; effects of daily administration of concentrates. California and West. Med., 1939, $50,125$.

5a. Rinehart, J. F., and Mettier, S. R., The joints in experimental scurvy and in scurvy with superimposed infection, with a consideration of the possible relation of scurvy to rheumatic fever. Am. J. Path. (Proc.), 1933, 9, 952.

b. Rinehart, J. F., Connor, C. L., and Mettier, S. R., Further observations on pathologic similarities between experimental scurvy combined with infection and rheumatic fever. J. Exper. Med., 1934, 59, 97.

c. Perla, D., and Marmorston, J., Rôle of vitamin C in resistance. Arch. Path., 1937, 23, 543 and 683.

6a. Schultz, Mark P., Studies of ascorbic acid and rheumatic fever; test of prophylactic and therapeutic action of ascorbic acid. J. Clin. Invest., 1936, 15, 385.

b. Finkle, P., Vitamin C saturation levels in the body in normal subjects and in various pathological conditions. J. Clin. Invest., 1937, 16, 587. 